\title{
Unstable Posterior Acetabular Fractures: Early Results of Delayed Reduction and Fracture Fixation Using the Kocher-Langenbeck Approach with Trochanteric Flip Osteotomy
}

\author{
Joseph L. Lai, Irewin A. Tabu and Majah S. Jacob \\ Section of Trauma, Department of Orthopedics, College of Medicine and Philippine General Hospital, University of the Philippines Manila
}

\begin{abstract}
Unstable posterior acetabular fractures resulting from high energy trauma present major challenges to any orthopedic surgeon especially if the treatment has been delayed.

Objective. The purpose of this paper is to describe the early results of delayed treatment of a series of patients with posterior acetabular fractures with concomitant hip dislocations, surgically approached using the Kocher-Langenbeck with a trochanteric flip osteotomy.
\end{abstract}

Methods. Five (5) male patients (mean age 35.6 years, range 2358 years) who sustained unstable posterior acetabular fractures, underwent surgical treatment using the Kocher-Langenbeck approach with the trochanteric flip osteotomy, during the period of May 2014 to October 2015. Clinical and radiographic evaluations of each patient were performed, while complications were documented.

Results. Mean follow-up was 8 weeks (range of 2-12 weeks). There was adequate exposure of the posterior and superior acetabulum in all patients. Post-operative radiographs in four of five patients were graded "anatomic," while hip range of motion of these four patients averaged $78.7 \%$ of the uninjured hip. One patient with "poor" reduction underwent a second operation to revise a failure of the initial fixation using the same surgical approach. No other complications were reported.

Conclusion. This modified approach provides adequate exposure of both posterior and superior acetabulum and also allows inspection of the articular surfaces of both acetabulum and femoral head, which are limited in the standard KocherLangenbeck approach. With excellent exposure, congruent reduction can readily be achieved while permitting early hip range of motion post-surgery.

Key Words: acetabular fractures, trochanteric flip osteotomy, Kocher-Langenbeck approach

Corresponding author: Joseph L. Lai, M.D.

Department of Orthopedics,

Philippine General Hospital

University of the Philippines Manila

Taft Avenue, Ermita, Manila 1000 Philippines

Telephone: +632 5548466

Email: jolaimd@yahoo.com
Introduction

The upsurge of motorcycle users especially in developing countries, has brought about a relative increase in the incidence of high energy trauma involving the acetabulum and hip areas., ${ }^{1,2}$ The more common acetabular fracture patterns seen in vehicular crashes are those involving the posterior wall and/or posterior column, with or without concomitant posterior hip dislocations. ${ }^{3,4}$ The hips of motorcycle riders are in a less flexed position of about 70 to 80 degrees. Impact directed posteriorly on this less flexed hip position may explain the involvement of the postero-superior to superior dome of the acetabulum in motorcycle crash victims. With delays in the administration of treatment due to various reasons such as late referral to a trauma center, polytrauma, and financial considerations, these hip injuries present a major challenge to any Orthopedic surgeon.

The principles of acetabular fracture management are currently based on the classification and surgical approach to the fracture. ${ }^{3,4}$ Adequate exposure of the fracture site permits anatomic reduction of the articular surface and provision of stable internal fixation of the acetabular fracture fragments. Achieving anatomic reduction is imperative to preserve hip function and to lessen the risk of post-traumatic osteoarthritis..$^{5-7}$ On the other hand, the desire to gain more exposure via extensile approaches may lead to additional injuries to the surrounding tissues which in turn, may result in complications such as infection, heterotopic ossification, and avascular necrosis of the femoral head.

The standard Kocher-Langenbeck approach is used mainly for posterior wall and column fractures and for certain transverse or T-shaped fractures of the acetabulum. This approach, however, permits limited access to the superior acetabular rim and therefore, limits fixation over this part of the acetabulum. Vigorous retraction of the posterior abductor muscles to improve visualization and fixation of the superior acetabulum, unfortunately, may increase the risk of ectopic ossification. At the same time, inspection of the intra-articular surfaces of the acetabulum and femoral head for possible osteochondral damage or marginal impaction injuries, is restricted in the KocherLangenbeck approach. ${ }^{8}$ 
The trochanteric flip osteotomy also called trochanteric 'slide' was first described by Mercati ${ }^{9}$ in 1972, and popularized by Glassman ${ }^{10}$ for the treatment of difficult primary and revision total hip arthroplasty. Over the past two decades, Siebenrock et al has adopted this approach for the treatment of posterior acetabular fractures. ${ }^{11-12}$ The addition of a trochanteric flip osteotomy has been reported to overcome the above-mentioned limitations of the standard Kocher-Langenbeck approach; while at the same time, keeping access morbidity such as trochanteric nonunion, hip abductor weakness and femoral head necrosis, at a minimum. ${ }^{11-15}$

In this study, we will describe our early experience with the use of the modified Kocher-Langenbeck approach with the trochanteric flip osteotomy for a series of patients with unstable posterior acetabular fractures associated with posterior hip dislocations.

\section{Methods}

From May 2014 to October 2015, five patients, all males, with an average age of 35.6 years (range of 23-58 years) were managed at the Department of Orthopedics of the University of the Philippines-Philippine General Hospital (UP-PGH) for unstable posterior acetabular injuries using the modified Kocher-Langenbeck approach with the trochanteric flip osteotomy. Their charts were retrieved and reviewed. Mechanism of injury was all due to high energy trauma, which included vehicular crashes in four patients, three of which were sustained by motorcycle riders; while one acetabular injury was due to a fall from a height. Fracture patterns according to Letournel and Judet ${ }^{8}$ included posterior wall fractures (4 patients) and a transverse with posterior wall fracture ( 1 patient). Other injuries noted were as follows: an ipsilateral femoral head fracture in one patient; another patient had a contralateral humeral shaft fracture and an ipsilateral $5^{\text {th }}$ metatarsal fracture; while another patient had rib fractures and pneumothorax which required chest tube thoracotomy. All five patients also sustained posterior hip dislocations. Closed reduction of the hip joint was performed beyond 24 hours post injury due to delayed presentation at the emergency room. After attaining hip reduction, stability was tested with the hip flexed to 45 degrees. All five patients, however, demonstrated instability when a posteriorly directed force was applied to their hip joints. Traction was applied afterwards to maintain hip reduction while preparing the patients for the definitive fixation of their posterior acetabular fractures.

Surgical fixation of the posterior acetabular fractures was performed around 12 days post injury (range 6-17 days). Surgical access was through the Kocher-Langenbeck approach modified with a trochanteric flip osteotomy. The indications for this approach were the hip instability in all five patients due to the large postero-superior acetabular fragment seen in the injury radiographs, and the need for surgical dislocation and internal fixation of the concomitant femoral head fracture in one patient. Table 1 summarizes the profiles of the patients in this series.

\section{Surgical Exposure and Technique}

The patients were placed in a lateral decubitus position on the operating table under general anesthesia. Typical skin incision for the Kocher-Langenbeck approach was used. After splitting the fascia lata in line with the skin incision, the gluteus maximus muscle and trochanteric bursa were incised longitudinally. The posterior border of the gluteus medius muscle up to its insertion onto the greater trochanter and the posterior border of the vastus lateralis muscle were defined and mobilized. A trochanteric or digastric osteotomy (Figure 1) was then made using an oscillating saw, making sure that the gluteus medius muscle insertion and entire origin of the vastus lateralis muscle were still attached with the osteotomized trochanter. To prevent damage to the deep branch of the medial circumflex femoral artery which may lead to femoral head necrosis, a small part of the most posterior portion of the gluteus medius tendon has to remain attached to the proximal femur. After the osteotomy, these fibers were then cut sharply, allowing the trochanteric fragment to be rotated or flipped 90 degrees and retracted anteriorly. The osteotomy runs lateral to the insertion of the short hip external rotators, which remained

Table 1. Patient profile

\begin{tabular}{|c|c|c|c|c|c|c|}
\hline Patient & $\begin{array}{c}\text { Age/ } \\
\text { Sex }\end{array}$ & $\begin{array}{c}\text { Mechanism of } \\
\text { injury }\end{array}$ & Posterior hip injuries & Other injuries & $\begin{array}{l}\text { Time from injury to } \\
\text { hip reduction (hrs.) }\end{array}$ & $\begin{array}{l}\text { Time from injury to } \\
\text { fracture fixation (days) }\end{array}$ \\
\hline 1 & $32 / \mathrm{M}$ & Vehicular crash & $\begin{array}{l}\text { Posterosuperior wall fracture L } \\
\text { Posterior hip dislocation L } \\
\text { Femoral head fracture L }\end{array}$ & $(-)$ & 16 & 6 \\
\hline 2 & $35 / \mathrm{M}$ & Motorcycle crash & $\begin{array}{l}\text { Transverse w/ posterior wall } \\
\text { fracture } \mathrm{R} \\
\text { Posterior hip dislocation } \mathrm{R}\end{array}$ & $(-)$ & 24 & 11 \\
\hline 3 & $30 / \mathrm{M}$ & Motorcycle crash & $\begin{array}{l}\text { Posterior wall fracture } \mathrm{R} \\
\text { Posterior hip dislocation } \mathrm{R}\end{array}$ & $\begin{array}{l}\text { Rib fracture, } \\
\text { pneumothorax }\end{array}$ & 17 & 14 \\
\hline 4 & $58 / \mathrm{M}$ & Motorcycle crash & $\begin{array}{l}\text { Posterosuperior wall fracture } \mathrm{L} \\
\text { Posterior hip dislocation } \mathrm{L}\end{array}$ & $\begin{array}{l}\text { Humeral shaft fracture } \mathrm{R}, \\
5 \text { th metatarsal fracture } \mathrm{L}\end{array}$ & $>24$ & 11 \\
\hline 5 & $23 / \mathrm{M}$ & Fall from height & $\begin{array}{l}\text { Posterior wall fracture } \mathrm{R} \\
\text { Posterior hip dislocation } \mathrm{R}\end{array}$ & $(-)$ & $>24$ & 17 \\
\hline
\end{tabular}


attached to the proximal femur at this point. The interval between the inferior border of the gluteus minimus muscle and the superior border of the piriformis tendon was defined and entered. Releasing the origin of the gluteus minimus muscle from the hip capsule allowed further mobilization of the trochanteric fragment anteriorly, and therefore, providing a wider exposure of the superior acetabulum. The short external rotator tendons, excluding the obturator externus and quadratus femoris muscles, were carefully incised $2 \mathrm{~cm}$ from their insertion on the proximal femur. This maneuver preserved the deep branch of the medial circumflex artery, gave further access to the posterior acetabulum, and also protected the sciatic nerve. With wide exposure of the posterior and superior acetabular rim, reduction and internal fixation of the fracture was then undertaken. Fixation was performed using $3.5 \mathrm{~mm}$ reconstruction plates and screws to buttress the posterosuperior acetabulum. Additional one-third tubular spring plate and/or interfragmentary screws were used for smaller comminuted fragments.

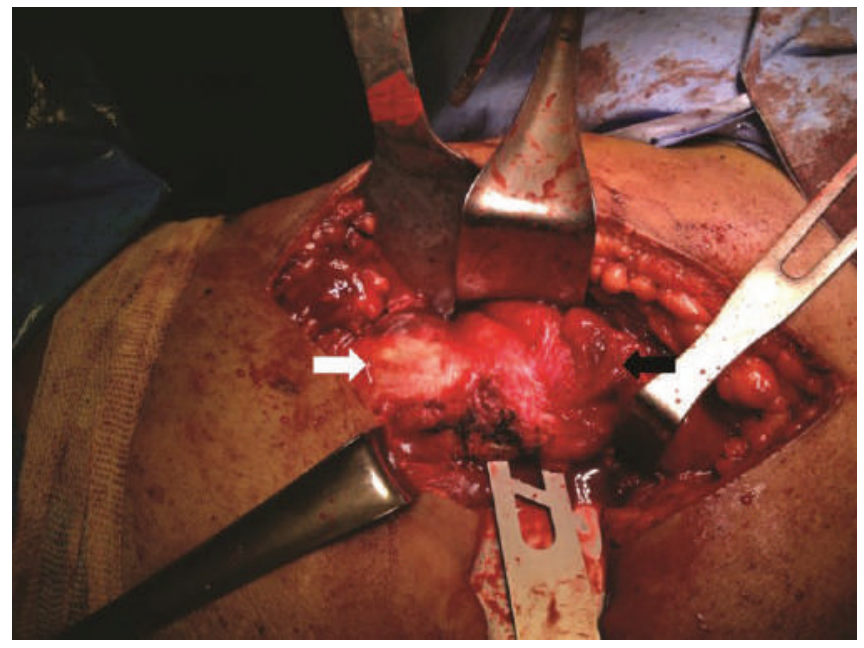

Figure 1. Trochanteric or digastric osteotomy. Trochanteric osteotomy is created using an oscillating saw, with the gluteus medius (white arrow) and vastus lateralis (black arrow) muscles still attached to it.

For the patient with a concomitant femoral head fracture (Figure 2), the same Kocher-Langenbeck exposure with the trochanteric flip osteotomy was utilized. The femoral head was re-dislocated posteriorly through the capsular tear. This allowed reduction and internal fixation with $2.2 \mathrm{~mm}$ cortical screws used as an interfragmentary fixation device. With the femoral head still dislocated, the articular surfaces of the femoral head and acetabulum were then inspected for any osteochondral damage or marginal impaction, while intraarticular fragments were removed.

After fixation of the acetabular and femoral head fractures and relocation of the femoral head into the hip joint, the osteotomized greater trochanter was reduced and internally fixed in compression with two $3.5 \mathrm{~mm}$ cortical screws. For a more accurate reduction of the trochanteric fragment and to minimize the risk of superior migration, a stepped cut was utilized. ${ }^{16}$

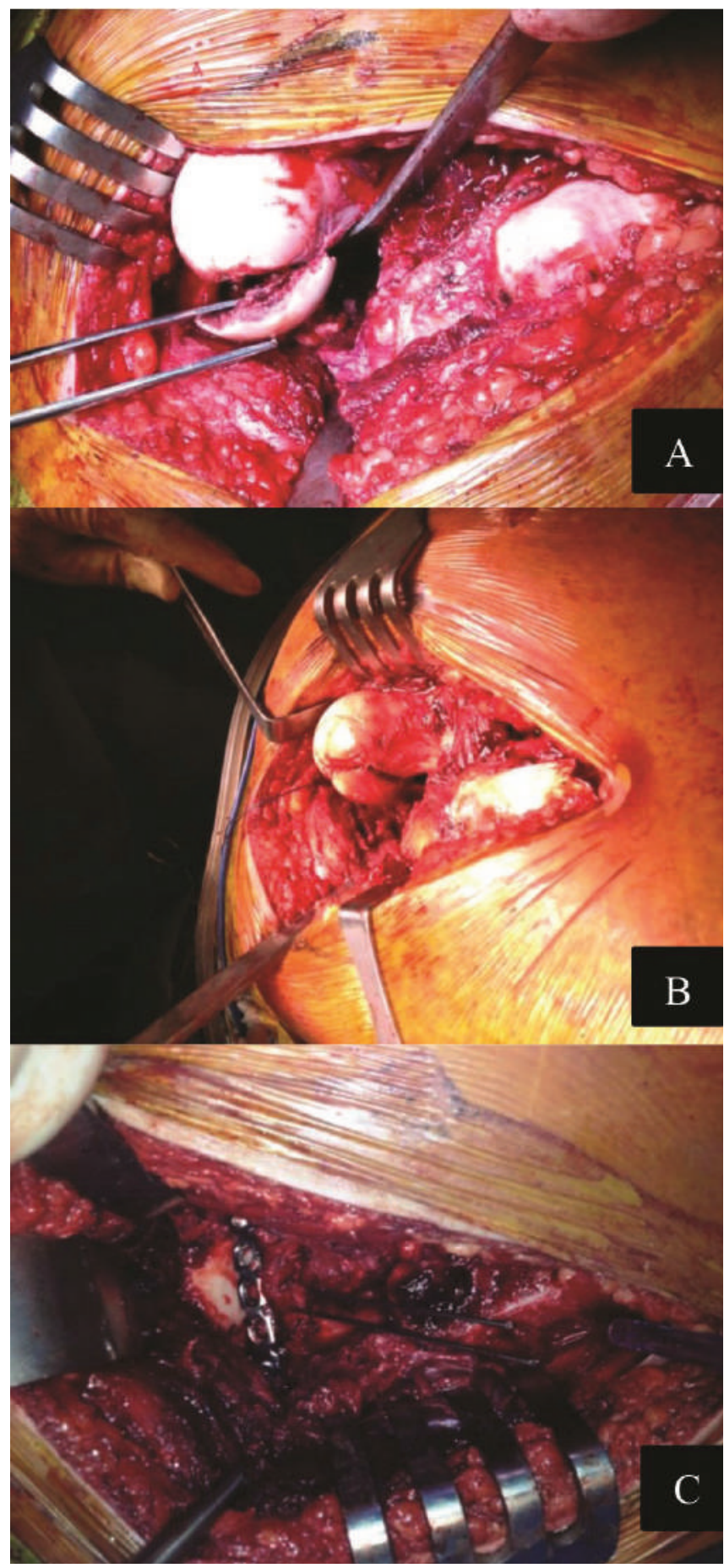

Figure 2. Patient with posterior acetabular fracture and concomittant femoral head fracture: A-B. Femoral head fracture is visualized and fixed with $2.2 \mathrm{~mm}$ cortical screws. C. Femoral head relocated within hip joint, posterior acetabular fracture is fixed with buttress plate and screws. 


\section{Post-operative evaluation}

Active range of motion of the operated hip (flexion, extension, abduction, adduction, internal and external rotation) was permitted immediately after surgery. The hip range of motion was measured using a goniometer, and compared to the uninjured hip as a percentage during each follow-up. The accuracy of fracture reduction was evaluated post-operatively on three standard radiographs

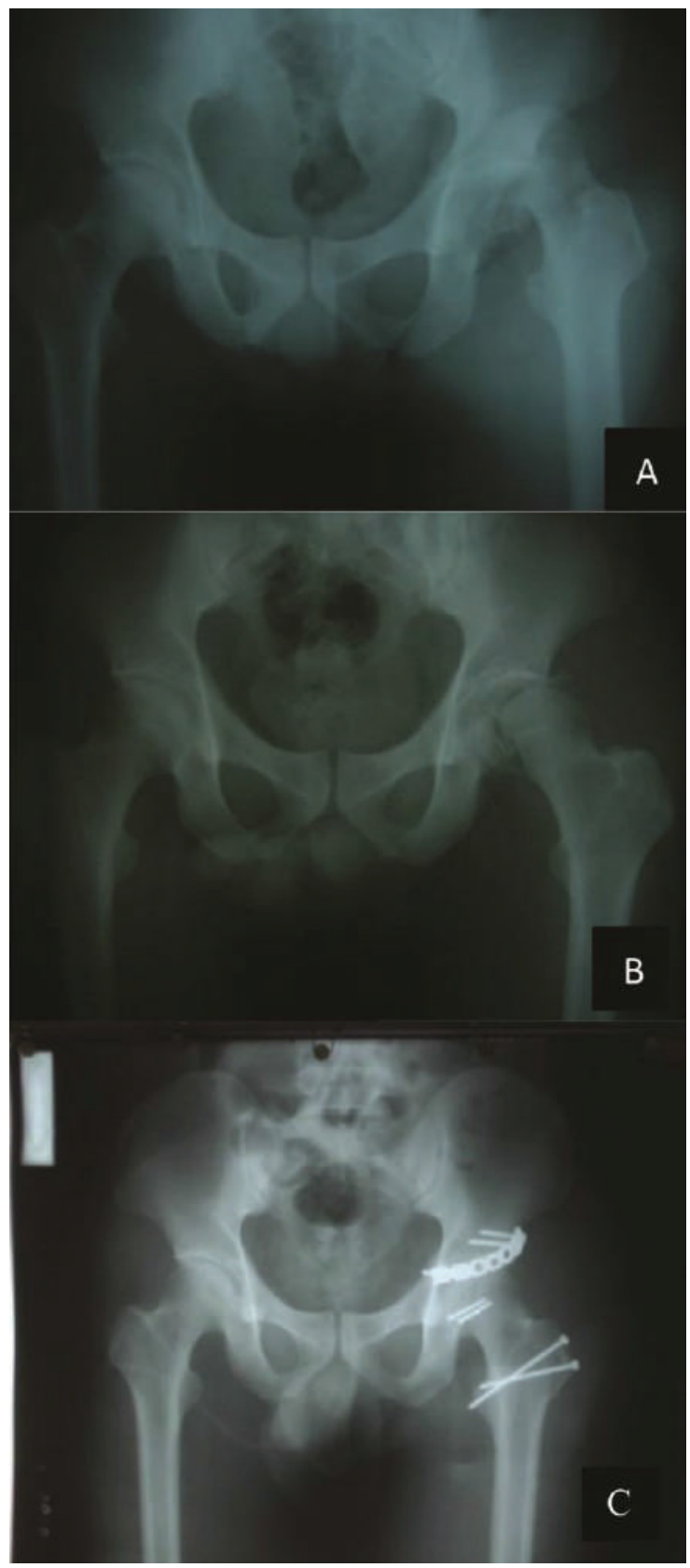

Figure 3. Pelvis AP radiographs of patient 1 with posterior acetabular fracture with concomitant posterior hip dislocation and femoral head fracture: A. Injury, B. Post closed reduction of posterior hip dislocation. C. Post fixation with "anatomic" reduction. (anteroposterior and two Judet $45^{\circ}$ oblique pelvic radiographs). According to $\mathrm{Matta}^{6}$, reduction can be graded as: "anatomic" if there was only 0 to $1 \mathrm{~mm}$ of displacement, "imperfect" if displacement was 2 to $3 \mathrm{~mm}$ and "poor" if it was more than $3 \mathrm{~mm}$. Complications such as failure of fixation of the acetabulum/head or trochanter, infection, ectopic ossification, avascular necrosis of the femoral head or sciatic nerve palsy were documented.

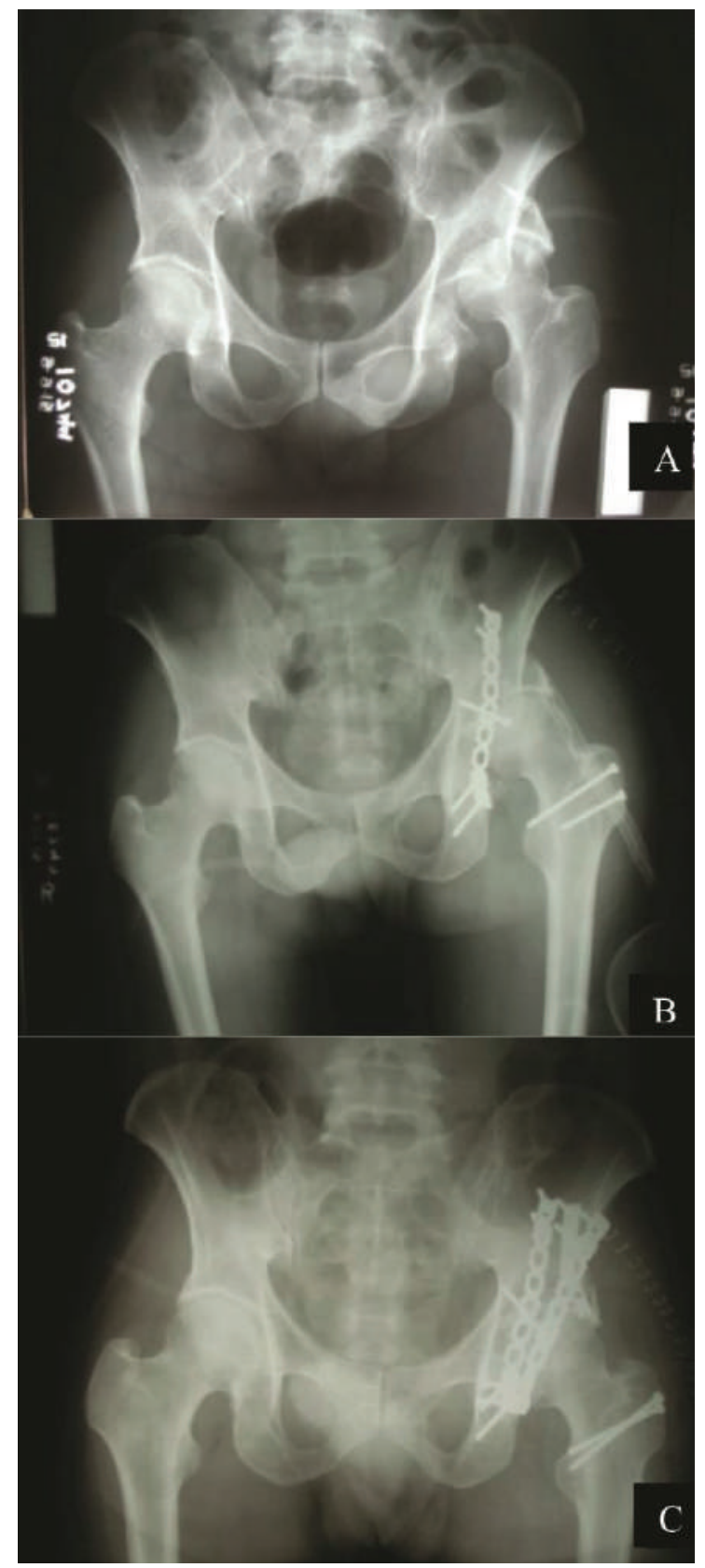

Figure 4. Pelvis AP radiographs of Patient 4. A. Injury film showing large postero-superior acetabular fragment. B. Post initial fixation which failed. C. Post revision fixation with 2 buttress plates and additional spring plate, assessed as "imperfect" reduction. 
Trochanteric Osteotomy for Posterior Acetabular Fractures

Table 2. Hip range of motion among study patients (normal vs operated)

\begin{tabular}{|c|c|c|c|c|c|c|c|c|c|c|}
\hline \multirow{2}{*}{$\begin{array}{l}\text { Hip range of } \\
\text { motion }\end{array}$} & \multicolumn{2}{|c|}{ Patient 1} & \multicolumn{2}{|c|}{ Patient 2} & \multicolumn{2}{|c|}{ Patient 3} & \multicolumn{2}{|c|}{ Patient 4} & \multicolumn{2}{|c|}{ Patient 5} \\
\hline & $\begin{array}{l}\text { Normal } \\
\text { (N) }\end{array}$ & $\begin{array}{c}\text { Operated } \\
(\% \text { of } N)\end{array}$ & $\begin{array}{l}\text { Normal } \\
\text { (N) }\end{array}$ & $\begin{array}{c}\text { Operated } \\
(\% \text { of } N)\end{array}$ & $\begin{array}{l}\text { Normal } \\
\text { (N) }\end{array}$ & $\begin{array}{l}\text { Operated } \\
(\% \text { of } N)\end{array}$ & $\begin{array}{l}\text { Normal } \\
\text { (N) }\end{array}$ & $\begin{array}{c}\text { Operated } \\
(\% \text { of } N)\end{array}$ & $\begin{array}{c}\text { Normal } \\
(\mathrm{N})\end{array}$ & $\begin{array}{l}\text { Operated } \\
\text { (\% of } N)\end{array}$ \\
\hline Flexion & 115 & $\begin{array}{c}108 \\
(93.9)\end{array}$ & 125 & $\begin{array}{c}98 \\
(78.4)\end{array}$ & 130 & $\begin{array}{c}130 \\
(100)\end{array}$ & 120 & $\begin{array}{c}70 \\
(58.3)\end{array}$ & 120 & $\begin{array}{c}110 \\
(91.7)\end{array}$ \\
\hline Extension & 30 & $\begin{array}{c}20 \\
(66.7)\end{array}$ & 30 & $\begin{array}{c}20 \\
(66.7)\end{array}$ & 26 & $\begin{array}{c}20 \\
(76.9)\end{array}$ & 30 & $\begin{array}{c}0 \\
(0)\end{array}$ & 40 & $\begin{array}{c}35 \\
(87.5)\end{array}$ \\
\hline Abduction & 50 & $\begin{array}{c}40 \\
(80)\end{array}$ & 50 & $\begin{array}{c}40 \\
(80)\end{array}$ & 60 & $\begin{array}{c}40 \\
(66.7)\end{array}$ & 50 & $\begin{array}{c}30 \\
(60)\end{array}$ & 60 & $\begin{array}{c}35 \\
(58.3)\end{array}$ \\
\hline Adduction & 30 & $\begin{array}{c}25 \\
(83.3)\end{array}$ & 30 & $\begin{array}{c}25 \\
(83.3)\end{array}$ & 35 & $\begin{array}{c}25 \\
(71.4)\end{array}$ & 30 & $\begin{array}{c}0 \\
(0)\end{array}$ & 30 & $\begin{array}{c}20 \\
(66.7)\end{array}$ \\
\hline Internal Rotation & 40 & $\begin{array}{c}40 \\
(100)\end{array}$ & 20 & $\begin{array}{c}20 \\
(100)\end{array}$ & 50 & $\begin{array}{c}40 \\
(80)\end{array}$ & 35 & $\begin{array}{c}10 \\
(28.6)\end{array}$ & 35 & $\begin{array}{c}20 \\
(57.1)\end{array}$ \\
\hline External Rotation & 30 & $\begin{array}{c}30 \\
(100)\end{array}$ & 30 & $\begin{array}{c}10 \\
(33.3)\end{array}$ & 40 & $\begin{array}{c}40 \\
(100)\end{array}$ & 45 & $\begin{array}{c}10 \\
(22.2)\end{array}$ & 30 & $\begin{array}{c}20 \\
(66.7)\end{array}$ \\
\hline $\begin{array}{l}\text { Ave. } \% \text { of Normal } \\
\text { per patient }\end{array}$ & & $87.3 \%$ & & $73.6 \%$ & & $82.5 \%$ & & $28.2 \%$ & & $71.3 \%$ \\
\hline
\end{tabular}

\section{Results}

The length of follow-up ranged from 2 to 12 weeks, with a mean of 8 weeks. Intra-operatively, adequate exposure of the entire posterior and superior acetabulum was easily achieved in all patients. Some fibroses were noted around the fracture fragments and the surrounding soft tissue however, these were still easily mobilized in spite of the definitive treatment being performed at two weeks or beyond after injury. Post-reduction radiographs in four of the five patients, including the patient with an associated femoral head fracture (Figure 3) were assessed as "anatomic." As of the latest follow-up, active hip range of motion for these four patients averaged $78.7 \%$ (range of $71.3 \%-87.3 \%$ ) of the uninjured hip (Table 2). Hip abduction was diminished the most with a mean loss of 16.25 degrees (average of $71.25 \%$ of the opposite hip). For the other ranges of hip motion (flexion, extension, adduction, internal and external rotation), the reduction ranged from 6.25 to 11 degrees.

One patient (Figure 4) with a large posterior wall fragment which extended to involve the superior acetabular rim was initially stabilized with a single buttress plate and an additional interfragmentary screw. Immediate postreduction radiographs, however, showed loss of reduction with the femoral head displaced superiorly with the superior rim fragment and therefore, was assessed to have a "poor" reduction. The initial fixation was deemed inadequate to maintain the reduction of the large posterosuperior fragment. A second surgery was performed a week later using the same approach. During this time, the exposure of the fracture was still adequate, allowing stabilization with an additional buttress and spring plates without necessitating extending the approach. Post-revision fixation radiographs were now graded as "imperfect." However, 8 weeks after the second operation, the patient still had a markedly limited hip motion, with a loss of 20 to 50 degrees for each range of motion or only achieving $28.2 \%$ of the opposite hip range of motion (Table 2). No other complications such as infection, ectopic ossification, osteonecrosis of the femoral head, sciatic nerve palsy nor trochanteric migration/non-union were reported as of the last follow-up for all five patients.

\section{Discussion}

The management of posterior acetabular injuries present numerous challenges to any Orthopedic surgeon. Since these injuries are usually due to high energy trauma, one should be cognizant and prepared to emergently manage polytrauma cases. Delays in performing closed reduction of the posterior hip dislocations, may lead to osteonecrosis of the femoral head which may only be evident several months after the injury. On the other hand, attaining accurate reduction and stable fracture fixation beyond two weeks from injury may be difficult due to adhesions and osteopenia of the fracture fragments. Inadequate evaluation of the injury may also lead to underestimating the bony and chondral lesions around the acetabulum and hip joint. Computed tomography ${ }^{7}$ is the preferred imaging tool; however, in developing countries, this may not be always available or affordable.

Another challenge in the management of unstable posterior acetabular injuries is the access to the posterior acetabulum/hip areas. The "gold" standard approach to the posterior acetabulum is the Kocher-Langenbeck which provides direct exposure of the lateral aspect of the posterior wall and column. ${ }^{8}$ However, exposure of the postero-superior up to the superior acetabular wall is limited. Inspection of the intraarticular surfaces of the femoral head and acetabulum is also restricted with this approach. With limited exposure, attainment of anatomic reduction and stable internal fixation may be compromised leading to poor outcomes. ${ }^{5-7}$ Vigorous retraction of the surrounding soft tissues just to gain extra exposure, unfortunately may increase complications such heterotopic ossification, infection, sciatic nerve palsy and avascular necrosis of the femoral head. 
Several modifications of the Kocher-Langenbeck approach have been proposed to create a more extensile exposure. One of these was the addition of an osteotomy of the greater trochanter with only the gluteus medius muscle attached to it, to gain better access to the hip joint. This was first described by Mercati $^{9}$ in 1972, and popularized by Glassman. ${ }^{10}$ The earlier use of this type of trochanteric osteotomy was for difficult primary and revision total hip arthroplasty. However, this access procedure was marred by complications such as trochanteric migration and nonunion. ${ }^{10}$ and hip abductor weakness. Besides these access morbidities, there was also note of longer operative time and more blood loss, all of which led to the decline of its usage.

In 1998, Siebenrock et al. ${ }^{11,12,15}$ revisited and modified this adjunct to the Kocher-Langenbeck approach, and termed it "trochanteric flip osteotomy". In Siebenrock's modification, the trochanteric osteotomy was created with both the gluteus medius muscle insertion and vastus lateralis muscle origin still attached to the osteotomized trochanter. This created a true digastric osteotomy wherein superior migration and non-union of the trochanter would be highly unlikely. A stepped osteotomy as described by Bastian et al. ${ }^{16}$ also allowed a more anatomic reduction and more stable fixation of the trochanter; thus, permitting early hip range of motion and less hip abductor weakness in the future.

Siebenrock also designed this approach to avoid damage to the deep branch of the medial femoral circumflex artery. ${ }^{11,12,15}$ The osteotomy should be done lateral to the insertion of the short hip external rotators, leaving them still attached to the femur; as such, the osteotomized trochanter should not be more than $1.5 \mathrm{~cm}$ thick. Afterwards, the short external rotators, excluding the obturator externus and quadratus femoris muscles, are incised $2 \mathrm{~cm}$. from their insertion onto the femur. These maneuvers will preserve the medial circumflex artery reducing the risk of osteonecrosis of the femoral head, and at the same time, protect the sciatic nerve and provide better exposure of the retro-acetabular area. In our series of patients, all of whom presented late for treatment, using this modified Kocher-Langenbeck approach is ideal to preserve the remaining blood supply to the femoral head. No avascular necrosis was noted even at 3 months post-operation; however, a longer follow-up is still needed to really determine the incidence of osteonecrosis with this modified exposure.

Although the trochanteric flip osteotomy has been in use for almost two decades now, it is only for the past couple of years that the authors have adapted this surgical access for the posterior acetabulum. The main indication for using this approach is the involvement of the superior acetabulum besides the usual posterior wall/column fractures. The necessity to inspect the articular surfaces of the hip joint (femoral head and acetabulum) for marginal impaction and osteochondral damage, for removal of intraarticular fragments, and for reduction and fixation of femoral head fractures are other indications for the addition of the trochanteric flip osteotomy to the standard KocherLangenbeck approach.

In our series of five patients with unstable posterior acetabular injuries, the modified Kocher-Langenbeck approach with the trochanteric flip osteotomy provided excellent exposure of the entire posterior and superior acetabular rims. Although, definitive surgery was done on the second to third week post-injury, the adhesions around fracture fragments and soft tissues were easily mobilized and did not require a more extensile approach. With this very adequate exposure, the authors achieved "anatomic" reduction in four of the five patients with stable fracture fixation. In the patient with a concomitant femoral head fracture, this approach also allowed direct visualization, reduction and fixation of the femoral head. The authors were also allowed to inspect the intraarticular surface of the acetabulum for any chondral damage and remove any fragments from within the hip joint. Ebraheim ${ }^{13}$ and Hadjicostas $^{14}$ reviewed their cases of trochanteric slide osteotomy for acetabular fractures, and both concluded that this technique enhanced the exposure of the acetabular dome and femoral head, while permitting a more accurate reduction and easier fixation of the acetabular fracture.

In our series, one patient had to undergo another surgery to revise the fixation of the postero-superior acetabulum. Using the same approach for both surgeries, the fracture fragments were well exposed and the application of additional fixation devices did not require extending the approach. The hip range of motion for this particular patient, however, was still markedly limited as of the last follow-up. This may be due to the additional soft tissue trauma, creating more adhesions and producing more pain for this patient. No other complications such as heterotopic ossification, infection, sciatic nerve palsy, avascular necrosis of the femoral head, and trochanteric non-union were recorded in the other four patients.

For the four patients who were assessed to have "anatomic" reduction, they were able to attain an average of $78.7 \%$ of the hip range of motion of the non-operated hip three months after surgery. This early results may project a seemingly favorable outcome for our patients, however, a longer follow-up of at least one year would be needed to fully evaluate the functional outcome of patients who underwent a trochanteric flip osteotomy to access their posterior acetabulum. Key outcomes such as pain, hip motor strength, walking ability and ability to perform activities of daily living and sports, besides congruency of reduction, hip range of motion, and presence of complications, should all be evaluated. A well-controlled comparative trial between the standard Kocher-Langenbeck approach and the one modified with the trochanteric flip osteotomy for the treatment of posterior acetabular injuries should also be undertaken to fully validate both access procedures. 


\section{Conclusion}

The addition of the trochanteric flip osteotomy to the standard Kocher-Langenbeck approach has sufficiently exposed not just the posterior acetabular wall and column but also the superior dome. Evaluation of the intraarticular hip joint is likewise permitted. With excellent exposure afforded by the addition of the trochanteric flip osteotomy, treatment of unstable posterior acetabular injuries will produce a more congruent reduction, allow earlier hip mobilization, with less morbidity, and better outcomes.

\section{References}

1. World Health Organization. Wetern Pacific Region. Areas of work: Road traffic injury [Online]. [cited 2015 Dec]. Available from http://www.who.int/philippines/areas/injury_violence/continuation_inj ury_and_violence_area_page/en/.

2. Geronilla MB, Sison JKT. Rash of motorcycle accidents: A growing national health concern. Acta Med Philipp. 2012; 46(2):5-8.

3. Judet R, Judet J, Letournel E. Fractures of the acetabulum. Classification and surgical approaches for open reduction. J Bone Joint Surg Am. 1964; 46:1615-46.

4. Letounel E. Acetabular fractures: Classification and management. Clin Orthop Relat Res. 1980; 151:81-106.

5. Giannoudis PV, Tzioupis C, Papathanassopoulos A, Obakponovwe O, Roberts C. Articular step-off and risk of post-traumatic osteoarthritis. Evidence today. Injury. 2010; 41:986-95.
6. Matta JM. Fractures of the acetabulum: Accuracy of reduction and clinical results in patients managed operatively within three weeks after the injury. J Bone Joint Surg Am. 1996; 78(11):1632-45.

7. Moed, BR, Carr SEW, Gruson KI, Watson JT, Craig JG. Computed tomographic assessment of fractures of the posterior wall of the acetabulum after operative treatment. J Bone Joint Surg Am. 2003;85A(3):512-22.

8. Letournel E, Judet R. The Kocher-Langenbeck approach. In: Reginald AE ed. Fractures of the Acetabulum, $2^{\text {nd }}$ ed. Berlin, Heidelberg, New York, Springer-Verlag; 1993. pp. 364-373.

9. Mercati E, Guary A, Myquel C, Bourgeon A. Une voie d'abord posteroexterne de la hanche. Interet de la realization d'un 'Muscle digastrique'. J Chir. 1972; 103(5):499-504.

10. Glassman AH, Engh CA, Bobyn JD. A technique of extensile exposure for total hip arthroplasty. J Arthroplasty. 1987; 2(1):11-21.

11. Siebenrock KA, Gautier E, Ziran BH, Ganz R. Trochanteric flip osteotomy for cranial extension and muscle protection in acetabular fracture fixation using a Kocher-Langenbeck approach. J Orthop Trauma. 2006; 20(1Suppl):S52--6.

12. Siebenrock KA, Gautier E, Woo AK, Ganz R. Surgical dislocation of the femoral head for joint debridement and accurate reduction of fractures of the acetabulum. J Orthop Trauma. 2002; 16(8):543-52.

13. Ebraheim NA, Patil V, Liu JY, et al. Sliding trochanteric osteotomy in acetabular fracture: a review of 30 cases. Injury. 2007; 38(10):1177-82.

14. Hadjicostas PT, Thielemann FW. The use of trochanteric slide osteotomy in the treatment of displaced acetabular fractures. Injury. 2008; 39(8):907-13

15. Keel MJ, Ecker TM, Siebenrock KA, Bastian JD. Rationales for the Bernese approaches in acetabular surgery. Eur J Trauma Emerg Surg. 2012; 38(5):489-98.

16. Bastian JD, Wolf AT, Wyss TF, Nötzli HP. Stepped osteotomy of the trochanter for stable, anatomic refixation. Clin Orthop Relat Res. 2009; 467(3):732-8.

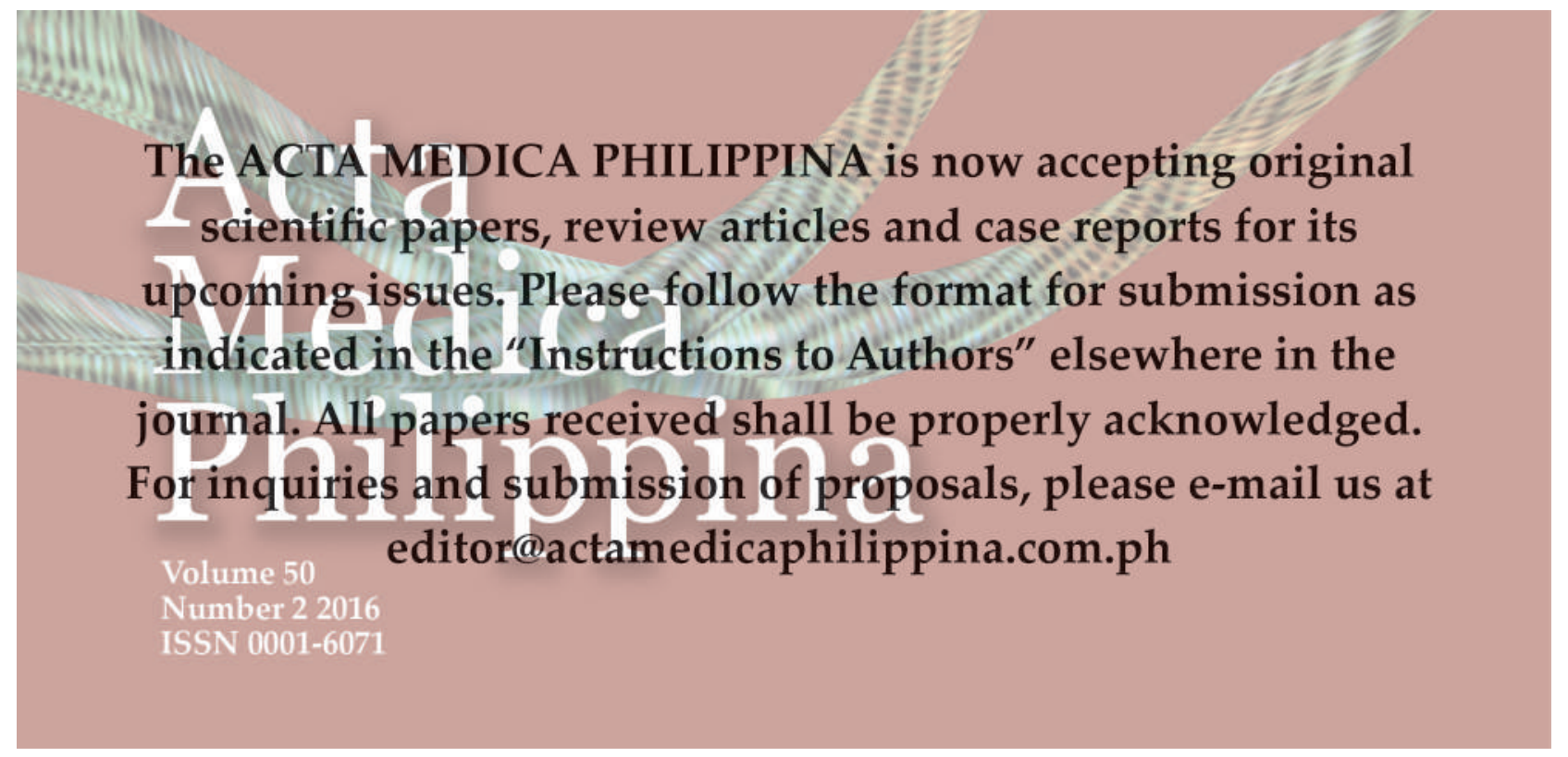

